\title{
Letting go of one's life story
}

\author{
Nils-Frederic Wagner \\ Department of Philosophy, University of Duisburg-Essen, Germany
}

\begin{abstract}
Persons are widely believed to be rational, planning agents that are both author and main character of their life stories. A major goal is to keep these narratives coherent as they unfold, and part of a fulfilled life allegedly stems from this coherence. My aim is to challenge these convictions by considering two related claims about persons and their lives. (1) Contrary to the widespread theoretical conviction in philosophy of mind and action, persons are more fundamentally emotional and affective rather than rational and deliberative beings. And so, (2) on a practical level, persons need not constantly aspire to integrate their past, present, and future into a coherent whole in order to live fulfilled lives. Needless to say, I cannot hope to defend these claims and their relation in great detail with a few brief strokes. In addition to theoretical reflections, I discuss some practical implications and potential benefits that come with discarding the daunting task of continuously keeping track of one's life story. Drawing on insights from a contemplative Buddhist tale, I contend that the practice of letting go can break the spell, and give rise to an alleviating source of liberation from life's troubles.
\end{abstract}

\section{Not so rational creatures}

Philosophers like to remind us that we, as rational people, have prudential reasons to do this, that and the other. We are planning agents with a prospective outlook on the future, shaped and formed by insights we've gained from past experiences. Our rationality is seen as the beacon guiding our thoughts and actions, steering us clear of the rocks-or at least it ought to be that way.

The ability to construct coherent life stories is, of course, a tremendous intellectual achievement that has evolved, probably evolutionarily, over a long period. Perhaps, as several influential contemporary philosophers claim, the narrative self is indeed a necessary condition of moral personhood. But, not only does the task of integrating past, present, and future into a coherent narrative unity sometimes seems like tilting at windmills, experience also teaches that we are, more often than not, far less rational and deliberative than we make ourselves believe.

It's not just that, the things that touch us most profoundly and connect us most directly with the human condition seldom get to us rationally or cognitively. Anybody who has ever fallen head over heels in love knows that rationality is the last source guiding one's behavior, and solving an equation is the last thing on one's mind when that happens. This just goes to illustrate that persons are by no means all-or even most fundamentallyrational creatures. Nor is this something worth aspiring to. The conviction that persons are by their very nature rational beings that live fulfilled lives by deploying their rationality-in 
the form of combining retrospection with planning agency-misses an important aspect; both theoretically and practically.

Since affects and emotions come mostly unfiltered, we have much less willful control over them than we have control over directing our rational thoughts and deliberations. In other words, we are more directly exposed to affects and emotions than we are to deliberation and rationality. This is by no means meant to aver that the former is more valuable than the latter, or to insist on a strict dichotomy between the two. It's just to emphasize that, by and large, affects and emotions are the most salient features that shape our lives, and as such constantly remind us of the human condition. So, considering that our nature is fundamentally emotional, nurturing affective stability might be more essential to fulfilment than deploying one's rational abilities.

What is sometimes called 'emotional intelligence' (or more poetically, nobleness of the heart) might in fact be a better guide to living fulfilled lives, for it connects us more directly with the human condition. To a first approximation, emotional intelligence can be defined as the ability to identify and utilize both our own emotions, and the emotions of others. By understanding ourselves more as emotional creatures and less as rational agents, it becomes also easier to be kind towards ourselves (and ultimately towards others), which is, in turn, according to Buddhism, an integral part of fulfillment.

In what follows, I will explore how a widespread conviction related to us being rational creatures-the idea that we ought to integrate past, present, and future into a coherent life story in order to live fulfilled lives-might not only be unnecessary but perhaps even obstructive to fulfilment. I submit that grasping the importance to let go of one's past and future by focusing on the present through affective and emotional means (rather than cognitively) enables us to directly connect with the existential reality of our life. It furthermore offers a source of liberation from, and consolation for, life's troubles.

\section{Coherent life stories, and experiential reality}

The alleged necessity of integrating one's past into a coherent life story, anticipating actions, planning projects, and mitigating risks of a future that fits the coherence of that story too, stems partly from the belief that life's value becomes most apparent when being looked at from a large (maybe even cosmic) scale. Things that occur over a considerable amount of time make sense and are worthwhile when they form a unity, or so goes the assertion. The parts that constitute our lives, therefore, must fit together neatly so that the puzzle of our existence finally reveals itself as a, more or less beautiful-but nevertheless well-pairedpicture. 
Curiously enough, this thought also implies that life can only ever be fully understood and evaluated retrospectively, reflecting on what has happened before; in light of a prospective outlook of what is yet to happen; and by constantly juggling the parts to ensure that all this aligns with what is happening now. Occasionally, when things go pear-shaped (as they inevitably do sometimes), we are starkly reminded of the need to change the course our lives have taken because we went astray; implying that if we continue to follow the current path, our life stories won't be coherent. This, again, looks at life from a bird's eye view. The three ingredients that are supposed to form the pursued narrative unity-past, present, and future-are taken together and evaluated regarding their coherence. By so doing, we transcend from the experiential reality of the present moment.

Now, here's the thing. When holding on to what has happened before, and anticipating what's going to happen next, the distinctiveness of the present moment gets largely lost from sight. Not only is the importance of the present moment as the only time that can truly be molded thereby underappreciated, but the experiential reality of that present is missed too. Whereas both past and future are merely thoughts arising in the present, this very moment is the only experiential reality of our existence. Surely, to some extent, the present is influenced by what has happened before, and it will shape what is going to happen next, but it is inherently different from the past and the future in that it is the only reality to which we have direct experiential access. The present moment is neither already over nor is it yet to come, but it is now. Wouldn't it be natural to assume, therefore, that this experiential reality is what matters most?

The aspiration to form a narrative unity fosters both lingering in the past and prefiguring the future, and thereby obfuscates the importance of, and connection to, the present. An idea that can be grasped both cognitively and emotionally. Considering some of the Buddhist teachings, I suggest that capturing this idea first and foremost emotionally is most effective to get at its significance for living fulfilled lives. A means to do so that doesn't require much reflection is by way of taking in stories and metaphors, the meaning of which we understand intuitively-nourishing the nobleness of the heart, as it were. Consider the following Buddhist tale.

\section{Let go of the banana}

In ancient times, it was easy to capture a monkey. The hunter would wander into a forest, find a ripe coconut, and cut out a small hole that was exactly the same size as a monkey's fist. He would then drink the sweet milk and eat some of the soft flesh.

Having eaten, he would secure the empty coconut to a tree with a thick rope or leather strap. After placing a banana inside the coconut, the hunter would go home. 
Sure enough, a monkey would discover that hollow coconut with a banana inside and try to pull it out. But the hole is only just big enough for a monkey to put in an empty fist. When his fist was holding the banana, he couldn't get it out.

By the time the hunter returns, the monkey has been struggling for hours to get his fist out together with the banana. Seeing the hunter, the monkey tries even harder to get both his fist and the banana out.

All the monkey needs to do to escape is to let go of the banana. Then he can pull his hand out and run. But does the monkey let go?

No way! Because monkeys always think, "It is my banana. I found it. It's mine!" And that is how monkeys get captured every time. ${ }^{i}$

Monkeys are experts on bananas; they love them to bits. Now imagine how this happening must have felt from the monkey's perspective: 'I've always loved bananas', the monkey surely thought when he discovered the tasty fruit inside the coconut. 'Having this banana will make me happy. If only I could hold on to it and finally get it out of that damn coconut, I'd add another banana to my banana life story! It'll all make sense.'

The monkey, identifying himself as a banana expert, is convinced that having this banana is what he needs to be happy-it has always been that way, and it will always be so. A false glimmer that prevents him from letting go of the banana. Now, the problem of course is that the monkey loses sight of the present. Being so captivated by the anticipated tastiness of the banana, he fails to recognize urging present matters. Getting captured by the hunter could have been avoided easily, if only he had just let go of the banana and found himself another one, or perhaps a mango. But that wasn't possible. Doing so would have disconnected him from his self-identification as a monkey with a banana expert history, and it would have taken away the anticipated reward of soon enjoying the delicious treat. In other words, letting go threatened the coherence of his banana life story.

Abstracting from this tale, it becomes apparent how a similar mechanism pulls people back into the past, or directs their attention to the future, away from the present. And that's how we get captured: 'It's my past, I own it, it defines who I am, and who I will be in the future. So I'd better make sure that what's happening now fits the story'-or so you might think facing some situation that would require your undivided attention. Lingering in the past prevents us from letting go of our life stories because we can't free ourselves from trying to figure out what has happened, and from settling the issue of how this will fit to what's going to happen next. By so doing, we hinder ourselves from being free in the present moment, fleeing from what occasionally comes to us naturally: taking in the here and now, leaving the past and future alone. I will now turn to saying more about this in terms familiar to analytic philosophy. 


\section{Identity, attachment, and letting go}

Attachment to our past stems partly from the fear of dropping our identity-the false conviction that by letting go of our past, we'll lose who we are. Similarly, refraining from anticipating the future threatens to take away a felt certainty of, and control over, a life story that has only ever been an illusion in the first place. Instead of realizing that by holding on to the past, and by anticipating the future, we confine ourselves to the prison cell of a fixed identity that leaves little room for embracing the present openly and charitably, receptive to where it might lead.

Another reason for the tendency to repudiate the present is the continuous hope of becoming happy and finding fulfillment in the future-a future that never arrives. And so even when we think we are in the present moment, we are really only looking over its shoulder, anticipating what's coming next, and trying to solve the problem of integration.

Closely related is the belief that we own our life stories. One part of ownership is having control over what one owns. Remaining in control over our life, for example, seems to imply that we must take charge of creating this coherent narrative that consists of past, present, and future. The fear is that, if we don't claim ownership over past, present, and future, our identity is going to be taken away from us. People have a hard time letting go of things they think they own-just like the monkey wouldn't let go of the banana. It is easy to forget that we neither own nor have control over the past and the future; but we do have control over the present. Not only is it liberating to be freed from attachment to the past and the future, but focusing on the present also offers a way to be in keeping with the human condition; embracing the affects and emotions that make up the present moment, and finding fulfillment there. Rather than ruminating on the coherence of a life story whose plot mainly consists of a past and future that allegedly constitute our identity.

Letting go of one's life story doesn't entail an attempt to erase what has happened before, or to disregard that there will be a future. It means getting rid of some of the baggage that attachment to both the past and the future carry in allegedly constituting a person's identity. One obvious point to consider is that we can neither change the past nor determine the future with any degree of certainty that would be needed in order to coherently integrate these elements. Whether we like it or not, we already are quite detached from the past and the future.

The Buddhist teachings of Anattā (the vanishing of the sense of self) and Anicca (the transience of all things) might help to further illustrate the connection between identity and attachment. We are attached to things that we claim ownership over, such as the assumption that we are the owner of our physical characteristics and our mental states that together form our personal identity over time. It seems as if there was an embodied permanent self that persists through time and change. Buddhists, however, think that this might be a trick 
that experiential recollection and anticipation play on us. When looking back on our lives and looking ahead, we recall and prefigure an experience from the perspective that we remember having had in said experience or expect to occupy in it. First-person experiences whose source, the enduring permanent self, appears to have remained unchanged. David Velleman has suggested that the illusory belief in a single self that appears to have its full existence both earlier and later, originates from the perception that the 'I' who remembers a past experience and the 'I' who anticipates a future experience become 'superimposed'. But in fact they are only ever loosely connected. ${ }^{\text {ii }}$

From a practical point of view, the metaphysical dispute over whether there is an enduring self need not be resolved in order to catch the importance of immersing into the present moment. Jeff McMahan tells us poignantly what can be gained from shifting our perspective from contemplating the past and the future to being attentive to the present:

The common exhortation to focus on the present may mean only to avoid becoming so preoccupied with the future that the goods of the present pass by unnoticed; or it may mean to adjust one's concern about the future to take account of uncertainty, for there is no point in sacrificing the present to evils that may never occur. It is also worse than pointless to contaminate the present with brooding about future evils when nothing can be done to avert them. Thus, in times of affliction the advice of the Reverend Sydney Smith, recently quoted with approval by John Bayley in his account of Iris Murdoch's descent into dementia, may make good sense: "Take short views of human life-never further than dinner or tea."iii

Adopting one of Derek Parfit's famous metaphors, when constantly trying to integrate past, present, and future into a coherent life story, our lives seem like glass tunnels, through which we move faster every year, and at the end of which there is darkness. When we change our view, let go of the past, free ourselves from continuously anticipating an inevitably uncertain future, and instead focus on whatever is true of our lives in the present, the walls of our glass tunnels disappear. We now live in the open air.

\footnotetext{
i Ajhan Brahm, Don't Worry, Be Grumpy: Inspiring Stories for Making the Most of Each Moment (Somerville: Wisdom Publications, 2014), p. 115.

ii D. Velleman, 'So It Goes', The Amherst Lecture in Philosophy, 1 (2006), pp. 1-23.

iii Jeff McMahan, The Ethics of Killing: Problems at the Margins of Life (New York: Oxford University Press, 2002), p. 82.
} 